\title{
ANALISIS KUALITAS LAYANAN DALAM MEMEDIASI PENGARUH HAR- GA, PRODUK, PEMASARAN RELASIONAL, DAN MCSQ TERHADAP KEP- UASAN PELANGGAN HOTEL BINTANG EMPAT DI KABUPATEN BADUNG, BALI
}

\author{
I Wayan Majuarsa, Widji Astuti, Grahita Chandrarin \\ Fakultas Ilmu Sosial dan Ilmu Politik Universitas Mahendradatta Denpasar \\ Email: iwayanmajuarsa2017@gmail.com
}

\begin{abstract}
Abstrak - Persaingan bisnis perhotelan di Kabupaten Badung Provinsi Bali semakin meningkat. Upaya yang dilakukan oleh manajemen hotel adalah dengan menentukan penawaran yang tepat untuk tetap bertahan di tengah persaingan dan dapat meningkatkan profitabilitas. Akan tetapi perusahaan akan mengalami kegagalan jika tidak didukung baik oleh internal perusahaan maupun pihak eksternal dalam perusahaan ini adalah pelanggan yang selalu menuntut kepuasan atas kinerja perusahaan perhotelan. Kepuasan pelanggan sebagai tingkat perasaan seseorang sebagai hasil dari perbandingan antara kenyataan dan harapan yang diterima dari suatu produk atau jasa. Penelitian ini bertujuan untuk membuktikan dan menganalisis pengaruh harga, produk, pemasaran relasional dan komitmen manajemen terhadap kualitas pelayanan dan kepuasan pelanggan hotel bintang empat di Kabupaten Badung Provinsi Bali. Populasi dalam penelitian ini adalah tamu hotel baik domestik maupun internasional yang menginap di hotel bintang empat di Kabupaten Badung Provinsi Bali dengan jumlah sampel 154 orang. Teknik analisis data menggunakan Structural Equation Modeling dengan SPSS 23 dan AMOS 18. Hasil pembahasan dapat disimpulkan bahwa harga dibentuk dari tarif yang diharapkan, tarif sesuai dengan keuntungan dan diikuti dengan tarif yang kompetitif maka terbentuk produk oleh produk inti dan diikuti oleh produk tambahan, pemasaran relasional dibentuk dengan menarik, dikembangkan, dan diikuti oleh mempertahankan dan komitmen manajemen pada kualitas layanan dibentuk oleh pemberdayaan dan diikuti oleh penghargaan. Harga, produk, pemasaran relasional dan komitmen manajemen terhadap kualitas pelayanan berpengaruh signifikan terhadap kualitas pelayanan hotel bintang empat di Kabupaten Badung Provinsi Bali. Harga, produk, pemasaran relasional dan komitmen manajemen terhadap kualitas pelayanan berpengaruh signifikan terhadap kepuasan pelanggan hotel bintang empat di Kabupaten Badung Provinsi Bali. Kualitas pelayanan berpengaruh signifikan terhadap kepuasan pelanggan hotel bintang empat di Kabupaten Badung Provinsi Bali. Harga, produk, pemasaran relasional dan komitmen manajemen terhadap kualitas pelayanan berpengaruh signifikan terhadap kepuasan pelanggan hotel bintang empat di Kabupaten Badung Provinsi Bali dengan variabel kualitas pelayanan sebagai variabel intervening.
\end{abstract}

Kata kunci: harga produk, pemasaran relasional, MCSQ, kualitas layanan.

\begin{abstract}
Hotel business competition in Badung regency Bali Province is increasing. Efforts to be taken by hotel management is to determine the right offer to stay afloat in the midst of competition and can increase profitability. However, companies will experience a failure if unsupported by both internal company and external parties in this company are the customers who always demand satisfaction for the performance of the hotel company. Customer satisfaction as the level of one's feelings as a result of the comparison between reality and expectations received from a product or service. This study aims to prove and analyze the influence of price, product, relational marketing and management commitment on service quality and customer satisfaction of four star hotel in Badung regency of Bali province. The population in this study is hotel guest both domestic and international staying in four star hotel in Badung regency of Bali Province and the sample is 154 people. The data analysis technique using Structural Equation Modeling with SPSS 23 and AMOS 18. The result of the discussion can be concluded that the Price is formed by the tariff as expected, the tariff according to benefit and followed by the competitive tariff, the Product is formed by the Core product and followed by additional Product, Relational Marketing
\end{abstract}


is formed by Attracting, Developed, and followed by Retaining and Management Commitment on Quality Services are formed by empowerment and followed by rewards. Price, product, relational marketing and management commitment on service quality significantly influence the quality of service of four star hotel in Badung regency of Bali Province. Price, product, relational marketing and management commitment on service quality have an effect on significant to customer satisfaction of four star hotel in Badung regency of Bali Province. Service quality significantly affects the customer satisfaction of four star hotel in Badung regency of Bali province. Price, product, relational marketing and management commitment on service quality significantly influence the satisfaction customer of four star hotel in Badung regency of Bali Province with service quality variable as intervening variable.

Keywords: price product, relational marketing, MCSQ, quality service.

\section{PENDAHULUAN}

Persaingan bisnis hotel kini semakin ketat yang mana ditandai dengan adanya penambahan terhadap fasilitas. Perusahaan-perusahaan perhotelan lalu mulai terdorong untuk memperkuat basis strateginya dengan konsep-konsep seperti customer focused atau market oriented culture untuk tetap mengakses pasar secara menguntungkan dan menjamin suatu pertumbuhan berkelanjutan (Ferdinand, 2006). Desain dari bangunan, interior dan eksterior kamar hotel, suasana yang tercipta di dalam kamar hotel, restoran serta makanan dan minuman yang dijual beserta keseluruhan fasilitas yang ada merupakan contoh produk yang dijual. Sedangkan layanan yang ditawarkan adalah keramah-tamahan dan ketrampilan karyawan hotel dalam upayanya melayani pelanggan. Dalam meningkatkan kepentingan tentang kepuasan pelanggan, perubahan teknologi yang cepat dan tantangan persaingan global menuntut efektifitas strategi pemasaran guna mempertahankan dan juga mengem- bangkan keunggulan bersaing suatu perusahaan.

Keberhasilan dalam persaingan pada lingkungan usaha yang selalu bergejolak, diperlukan suatu strategi-strategi pemasaran berorientasi pasar yang dapatmengantisipasi keinginan pelanggan. Hal tersebut sangatlah penting dilakukan, apalagi setelah krisis ekonomi berkepanjangan sejak pertengahan tahun 2008 berdampak pada perkembangan bisnis perhotelan di Indonesia mengalami berbagai kendala. Banyak pula perusahaan perhotelan terpaksa harus melakukan merger atau akuisisi, agar dapat survive di tengah persaingan yang sangat ketat.

Pulau Bali merupakan tujuan wisata Indonesia yang sangat diminati. Hal tersebut mendorong terjadi pertumbuhan industri jasa perhotelan di Bali. Berdasarkan data Dinas Pariwisata Provinsi Bali, total hotel pada tahun 2016 terdapat 547 hotel. Daftar hotel berbintang tersebut tersaji berikut ini:

Tabel 1

Klasifikasi Hotel Berbintang di Provinsi Bali Tahun 2016

\begin{tabular}{|c|l|c|c|}
\hline No & \multicolumn{1}{|c|}{ Klasifikasi } & Jumlah Hotel & Persentase (\%) \\
\hline 1. & Bintang 5 & 66 & 34,74 \\
\hline 2. & Bintang 4 & 75 & 39,47 \\
\hline 3. & Bintang 3 & 49 & 25,79 \\
\hline & Total & $\mathbf{1 9 0}$ & $\mathbf{1 0 0 , 0 0}$ \\
\hline
\end{tabular}

Sumber: Dinas Pariwisata Provinsi Bali 2016 (diolah) 
Berdasarkan data-data Tabel 1 di atas menunjukkan bahwa jumlah hotel bintang empat memiliki prosentase terbesar yaitu $39,47 \%$, kemudian bintang lima sebanyak $34,74 \%$, dan paling sedikit hotel bintang tiga sebanyak 25,79\%. Sedangkan berdasarkan Tingkat Penghunian Kamar
(TPK) di tahun 2010-2014, secara umum baik dari hotel bintang tiga hinggabintang lima mengalami fluktuasi yang bervariasi. Terjadi perbedaan antara kenaikan dan penurunan baik hotel pada kelas bintang lima hingga bintang tiga. Berikut data jumlah kamar yang secara rinci:

Tabel 2

Jumlah Kamar Hotel Berbintang di Provinsi Bali Tahun 2016

\begin{tabular}{|c|l|c|c|}
\hline No & Klasifikasi & Jumlah Kamar & Persentase (\%) \\
\hline 1. & Bintang 5 & 15.081 & 50,59 \\
\hline 2. & Bintang 4 & 10.732 & 36,00 \\
\hline 3. & Bintang 3 & 3.997 & 13,41 \\
\hline & Total & $\mathbf{2 9 . 8 1 0}$ & $\mathbf{1 0 0 , 0 0}$ \\
\hline
\end{tabular}

Sumber: Dinas Pariwisata Provinsi Bali 2016 (diolah)

Berdasarkan Tabel 2 menunjukkan bahwa jumlah di dalam kamar hotel bintang lima sebanyak 15.081 kamar atau 50,59\%. Bintang empat sebanyak 10.732 kamar atau $36 \%$, dan paling sedikit adalah bintang tiga sebanyak 3.997 kamar atau $13,41 \%$. Hal ini menunjukkan bahwa antara jumlah kamar hotel bintang lima dengan bintang empat terdapat perbedaan yang cukup signifikan. Dari itu, perbedaan yang cukup signifikan mengindikasikan bahwa investor (pemilik) hotel cenderung berinvestasi pada hotel bintang lima daripada hotel bintang empat. Selain karena tarif hotel dan fasilitas yang tidak terpaut jauh, maka itulah investor juga memperhatikan trend masyarakat terutama wisatawan domestik yang ingin traveling dan menginap di hotel berbintang. Faktor lainnya adalah pesaing yang dihadapi hotel bintang empat, bukan hanya hotel yang mempunyai fasilitas dan pelayanan yang sama, tetapi juga dari hotel yang mempunyai fasilitas yang mewah untuk tujuan wisata. Berbagai fasilitas dan pelayanan yang sudah melekat pada hotel berbintang itu membuat tingkat hunian hotel berbintang meningkat.

Tingkat Penghunian Kamar (TPK) hotel berbintang di Bali pada tahun 20102014 secara umum mengalami fluktuasi yang bervariasi. Terjadi perbedaan antara kenaikan dan penurunan hotel berbintang. Berikut ini data tingkat hunian hotel yang secara rinci dapat dilihat pada Tabel 3.

Tabel 3

Tingkat Penghunian Kamar (TPK) Hotel Berbintang di Provinsi Bali Tahun 2010-2014

\begin{tabular}{|c|c|c|c|}
\multirow{2}{*}{ Tahun } & \multicolumn{3}{|c|}{ Klasifikasi Hotel } \\
\cline { 2 - 4 } & Bintang 5 & Bintang 4 & Bintang 3 \\
\hline 2010 & 3,73 & 3,70 & 3,88 \\
\hline 2011 & 3,61 & 3,50 & 3,65 \\
\hline 2012 & 3,54 & 3,40 & 3,40 \\
\hline 2013 & 3,51 & 3,37 & 3,43 \\
\hline 2014 & 3,42 & 3,33 & 3,27 \\
\hline
\end{tabular}

Sumber: Dinas Pariwisata Provinsi Bali 2014 (diolah)

Secara umum, perbedaan di antara Hotel berbintang adalah luas kamar yang disediakan, jumlah kamar yang tersedia, dan fasilitas yang sudah tersedia di hotel. Hotel jenis bintang 4 memiliki fasilitas yang sama seperti hotel bintang 5, akan tetapi dari segi harga tentu bersaing dengan hotel bintang 3, dengan demikian maka menarik untuk dikaji kepuasan pelanggan hotel bintang 4 . 
Upaya-upaya ditempuh manajemen hotel adalah dengan menentukan penawaran yang tepat supaya tetap bertahan di tengah persaingan serta dapat lebih meningkatkan profitabilitas. Namun, perusahaan bisa saja mengalami kegagalan memberikan kepuasan pelanggan apabila tanpa didukung baik oleh pihak internal perusahaan maupun pihak eksternal perusahaan. Kotler dan Keller (2008:117) dari itu mendefinisikan kepuasan pelanggan sebagai perasaan seseorang sebagai hasil dari perbandingan antara kenyataan dan harapan yang diterima dari sebuah produk atau jasa. Jika jasa yang dipersepsikan kinerjanya lebih rendah dari yang diharapkan, maka konsumen akan merasa kecewa dan sebaliknya. Dalam menciptakan kepuasan dengan pelanggan, perusahaan harus dapat lebih meningkatkan customer value yang dibutuhkan pelanggan dengan memberikan keunggulan produk (product advantage) dan harga yang bernilai sepadan. Seperti pendapat Hu, Kandampully and Juwaheer (2009 : 115-116) If the performance matches or exceeds the expectations, then the customer is satisfied, if performance is below then the customer is dissatisfied". Customer satisfaction is influenced by expectations, perceived service and perceived quality.

Kualitas pelayanan tidak lepas dari dukungan di internal perusahaan, terutama dukungan dari manajemen. Perusahaan yang produknya bervariasi dan bermutu tinggi, dengan harga bersaing akan dapat bersaing dengan produk lain yang sejenis dan dapat menarik dan memuaskan pelanggan. Produk menjadi instrumen vital untuk mencapai kesuksesan. Di lain sisi, perkembangan atas teknologi, peningkatan persaingan global, serta dinamika kebutuhan dan keinginan pasar, mengharuskan perusahaan perhotelan melakukan pengembangan dengan membuat harga sewa kamar per hari menjadi kompetitif, namun fasilitas maksimal. Selain itu pula, hotel dituntut memberikan kualitas layanan yang lebih prima. Berarti pelanggan betul-betul merasakan kenyamanan dalam menerima layanan dari pihak hotel. Kualitas layanan yang dimaksud meliputi fasilitas yang sangat memuaskan, mulai dari kamar hotel, tata ruang, para karyawan yang ramah, tanggap, dan peduli pada pelanggan.
Kualitas pelayanan yang dikelola secara baik akan memberi hasil yang baik untuk dapat memenuhi kepuasan pelanggan. Pelanggan memiliki kebebasan memberikan penilaian apakah produk-produk jasa yang ditawarkan pihak hotel memberi kepuasan sesuai yang diinginkan atau tidak. Malhotra dan Mukherjee (2004) dan Hella (2011) menyimpulkan ada pengaruh positif dan signifikan antara kualitas layanan diberikan karyawan terhadap kepuasan pelanggan. Morgan dan Hunt (2004:23), menyatakan bahwa komitmen sebagai keinginan yang terus menerus untuk memelihara kualitas layanan yang bernilai. Pelanggan memberi komitmen untuk bisa berkunjung ke hotel kembali guna menikmati layanan untuk memenuhi harapan pelanggan pada hotel. Malhotra dan Mukherjee (2004) menyatakan kualitas layanan yang diberikan oleh karyawan yang berhadapan langsung dengan konsumen berpengaruh pada kepuasan bagi pelanggan. Namun, kualitas layanan tidak dapat optimal jikalau tidak disertai dengan komitmen organisasional yang dilukiskan oleh MCSQ, seperti pernyataan disampaikan Babakus (2003:276) management commit- ment to service quality (MCSQ) is a critical determinant of employee behaviors in creating service excellence. Dapat diartikan MCSQ merupakan penentu penting dalam menciptakan layanan prima. Menurut Ashill (2008:442) supportive management characterises management concerns and support for employee work and represents the degree to which they create a facilitative climate of support, trust and helpfulness. Dukungan manajemen yang berupa mana- jemen yang berfokus pada karakteristik dan dukungan karyawan dalam bekerja serta lingkungan yang mendukung kepercayaan memegang peran penting dalam memuaskan pelanggan.

Pelanggan yang terpenuhi harapan atas produk atau layanan yang diberikan, akan menimbulkan kepuasan pelanggan sehingga membuat pelanggan melakukan pembelian ulang (repurchase) di masa yang akan da- tang dan mereferensi orang lainnya untuk mengikuti (word of mouth). Pada intinya pemasaran terdapat tiga komponen penting kegiatan yaitu perusahaan (manajemen) sebagai pihak yang menawarkan produk dan menetapkan harga 
kepada konsumen (pemasaran eksternal), karyawan sebagai penyampai jasa memerlukan manajemen yang memelihara dan mengembangkan karyawan (pemasaran internal). Kegiatan pemasaran ketiga yaitu kegiatan pemasaran interaktif, dengan mendorong agar tercipta hubungan yang baik di antara karyawan dengan pelanggan (pemasaran relasional). Membangun hubungan dengan pelanggan pada produk jasa seperti hotel berperan dalam menarik minat pelanggan untuk melakukan pembelian ulang. Pemasaran relasioal (relationship marketing) merupa- kan keunggulan daya saing berkelanjutan, karena tercipta hubungan jangka panjang dengan pelanggan terutama pada produk-produk yang non convenient.

Pemasaran relasional adalah suatu filosofi menjalankan bisnis yang fokus terutama pada perbaikan pelayanan pelanggan yang sudah ada dibandingkan dengan men- cari pelanggan baru. Berdasarkan definisi tersebut maka dapat dikatakan relationship marketing merupakan upaya guna mengenal konsumen lebih baik, sehingga perusahaan dapat memenuhi needs and wants konsumen dalam jangka panjang (Zeithmal dan Bitner., 2006:138). Dasar pemikiran dalam praktik pemasaran adalah bahwa jalinan hubungan dengan pelanggan ini dianggap menghemat biaya dibanding dengan mencari pelanggan baru atau mendapatkan pelanggan lama yang sudah putus hubungan. Memang terjalinnya hubungan jangka panjang antara pemasar dengan pelanggan bermula dari terciptanya transaksi, kemudian transaksi serupa diulang kembali sehingga akhirnya menjadi jalinan hubungan jangka panjang.

\section{Tujuan penelitian ini adalah:}

1. Untuk mendeskripsikan harga, produk, pemasaran relasional dan MCSQ, kualitas layanan dan kepuasan pelanggan hotel bintang empat di Kabupaten Badung Provinsi Bali.

2. Untuk menganalisis pengaruh harga, produk, pemasaran relasional dan MC SQ terhadap kualitas layanan hotel bintang empat di Kabupaten Badung Provinsi Bali.

3. Untuk menganalisis pengaruh harga, produk, pemasaran relasional dan MC SQ terhadap kepuasan pelanggan hotel bintang empat di Kabupaten Ba-

\section{dung Provinsi Bali.}

4. Untuk menganalisis pengaruh kualitas layanan terhadap kepuasan pelanggan hotel berbintang empat di Kabupaten Badung Provinsi Bali.

5. Untuk menganalisis pengaruh harga, produk, pemasaran relasional dan MC SQ terhadap kepuasan dari pelanggan melalui kualitas layanan hotel bintang empat di Kabupaten Badung Provinsi Bali.

\section{TINJAUAN PUSTAKA \\ a. Harga}

Menurut Berkowitz (200:314), "Price is the money or other considerations (including other goods and services) exchanged for the ownership or use of good or service." Kotler dan Amstrong (2012) mengartikan harga sebagai jumlah nilai yang dipertukarkan oleh pelanggan untuk memiliki manfaat atau menggunakan jasa. Berarti harga adalah sejumlah uang atau wujud lain termasuk barang dan jasa sebagai ganti kepemilikan dari barang dan jasa. Harga merupakan hal yang diperhatikan konsumen saat melakukan pembelian. Sebagian konsumen bahkan mengidentifikasikan harga dengan nilai.

Menurut Yee dan Sidek (2008), harga secara signifikan mempengaruhi pilihan konsumen dan pembelian. Dia menekankan bahwa potongan harga untuk peralatan rumah tangga membuat konsumen berganti merek dan membeli produk lebih awal dari yang diperlukan. Harga digambarkan se- bagai jumlah pembayaran atau kompensasi untuk sesuatu. Hal ini mengindikasikan harga sebagai rasio pertukaran antara barang-barang yang saling membayar satu sama lain. Harga adalah suatu pertimbangan penting bagi konsumen rata-rata. Namun konsumen dengan loyalitas merk yang tinggi tidak sensitif terhadap harga, sehingga selama konsumen merasa puas dengan merek tertentu, akan membelikan kembali produk dengan merk yang sama meskipun harga sangat mahal. Pernyataan tersebut mengindikasikan bahwa harga mempunyai pengaruh yang positif terhadap kepuasan pelanggan.

\section{b. Produk}

Produk dan konsumen amat berperan sebagai stimulus satu sama lain (Hoch dan Deighton, 2009). Kotler et.al (2012) 
berpendapat bahwa produk adalah segala sesuatu yang dapat ditawarkan ke pasar untuk lebih bisa menarik perhatian, dimiliki, digunakan atau pun dikonsumsi yang dapat memuaskan keinginan dan kebutuhan. Menurut Hoch dan Deighton (2009) proses pembelajaran yang mempengaruhi di antara familiaritas terhadap produk. Ketika konsumen tidak familiar terhadap produk, maka perusahaan dapat mempengaruhi proses pembelajaran meskipun lambat. Tanpa familiaritas, keyakinan terdahulu cenderung lemah dan konsumen menjadi tidak mampu membuat dugaan untuk mengorganisir pengalaman yang kompleks.

Produk adalah segala sesuatu yang dapat ditawarkan ke pasar untuk mendapatkan perhatian, dibeli, dipergunakan atau dikonsumsi dan dapat memuaskan keinginan atau kebutuhan konsumen (Daryanto, 2011). Klasifikasi mengenai produk menurut Daryanto (2011) terdiri atas: Produk konsumen dan produk industri.

\section{c. Pemasaran Relasional}

Pemasaran relasional menunjukkan ada suatu perubahan penting pada sistem nilai dan orientasi filosofis. Hal ini ditandai dengan teori pemasaran baru, kepuasan pelanggan masih dipandang perlu namun tidak lagi cukup sebagai tujuan pemasaran. Tujuan dalam mengembangkan hubungan dilakukan berdasarkan satu struktur manfaat jangka panjang dan ikatan antara pembeli dan penjual. Variabel yang menandai adalah network relationship meliputi kepercayaan (trust), komitmen dan norma sosial. Berry (2002:236) mengistilahkan dan mendefinisi- kan "Relationship Marketing is attracting, maintaining and- in multi-service organization-enhancing custome relationships."

Definisi ini menekankan bahwa pemasaran relasional merupakan tahap lebih lanjut untuk mempertahankan pelanggan, yaitu membina hubungan dengan pelanggan agar tetap loyal pada perusahaan. Berry dan Parasuraman (1991:133) menyatakan bahwa "relationship marketing concerns attracting, developing, and retaning customer relationships." Dengan cara yang sama, Morgan and Hunt (2004) mengemukakan bahwa "relationship marketing refers to all marketing activities directed toward establising, developing, and maintaining succesfull relationsl exchanges". Dapat di- artikan pemasaran relasional adalah semua kegiatan pemasaran yang diarahkan untuk membangun, mengembangkan dan memper- tahankan kesuksesan pertukaran relasional. Parvatiyar dan Sheth (1995) memandang "pemasaran relasional sebagai suatu orientasi yang mengembangkan interaksi erat dengan pelanggan terpilih, pemasok dan pesaing untuk penciptaan nilai melalui usaha kerjasama."

\section{d. MCSQ}

Menurut Hartline and Ferrell (1996:

59) MCSQ sebagai “the manager's affective desire to improve his or her unit'sservice quality". Di samping mempengaruhi service performance, MCSQ juga berpengaruh ter- hadap kepuasan, sebagaimana pandangan Tjahyono (2012) dan Kasiman (2012) yang menyatakan bahwa MCSQ berpengaruh signifikan terhadap kepuasan pelanggan. Pandangan tersebut sejalan dengan Cronin et al (1992) bahwa service performance berpengaruh signifikan terhadap tingkat kepuasan pelanggan.

Menurut Babakus (2003:273), management commitment to service quality is a critical determinant of employee behaviors in creating service excellence. Dapat diartikan komitmen manajemen memegang peran penting dalam mendukung keberhasilan usaha. Bowen and Lawler, (1995:76), Hartline et al., (1990:151) mengembangkan indikator MCSQ as training, empowerment and rewards. Indikator MCSQ mengacu pada pendapat Ashill, et al (2008 : 460-461) yang terdiri; (1) training, (2) empowerment, (3) employee reward, (4) supportive management, (5) servant leadership dan (6) investment in technology.

\section{e. Kualitas Layanan}

Menurut Duffy (2008), kualitas mengenai layanan berkaitan dengan persepsi pelanggan terhadap pelayanan yang akan diterima dari perusahaan. Kotler (2011), memandang kualitas layanan secara prinsip mengandung pengertian bahwa kualitas harus dimulai dari kebutuhan dan keinginan pelanggan, dan berakhir pada persepsi pelanggan. Persepsi pelanggan terhadap kualitas pelayanan merupakan penilaian yang menyeluruh atas keung- 
gulan suatu produk atau jasa. Kualitas pelayanan merupakan komponen penting dalam persepsi konsumen, juga sangat penting dalam mempengaruhi kepuasan konsumen.

Menurut Engel (2005) memaknai kualitas layanann adalah evaluasi pasca konsumsi dimana suatu alternatif yang dipilih minimal memenuhi atau melebihi harapan. Parasuraman (2012) mmengembangkan factor-faktor penentu kualitas layanan yaitu tangible, reability, responsiveness, empathy dan assurance.

\section{f. Kepuasan Pelanggan}

Kepuasan pelanggan adalah perasaan senang atau kecewa seseorang yang muncul setelah membandingkan antara kinerja (hasil) produk yang dipikirkan terhadap kinerja yang diharapkan (Kotler, 2005:70). Pada 2010, Kotler and Amstrong mendefinisikan kepuasan pelanggan merupakan suatu tingkatan dimana produk dirasakan sesuai dengan harapan pembeli. Kepuasan konsumen terhadap pembelian tergantung pada kinerja produk aktual, sehingga sesuai dengan harapan pembeli. Jika keberadaan suatu produk berada di bawah harapan pembeli, maka pembeli itu tidak akan merasa puas. Jika sesuai dengan harapan, maka konsumen akan merasa puas.

Kepuasan pelanggan dikaitkan dengan tingkat di mana produk dan jasa memenuhi kebutuhan dan keinginan pelanggan. Ke- puasan pelanggan merupakan perbandingan antara persepsi pelanggan terhadap suatu produk dengan harapan pelanggan. Kepuasan pelanggan adalah kunci yang penting untuk dapat mempertahankan pelanggan. Tanpa ada kepuasan pelanggan, perusahaan akan sulit bertahan dalam menghadapi persaingan. Hal tersebut sesuai dengan definisi yang dikemukakan Kotler (2012:18) yaitu, "The key to customer retention is customer satisfaction". Dapat diartikan untuk retensi dari pelanggan adalah kepuasan pelanggan.

\section{g. Hipotesis}

H1 : Harga, produk, pemasaran relasional dan MCSQ berpengaruh signifikan terhadap kualitas layanan

H2 : Harga, produk, pemasaran relasional dan MCSQ berpengaruh signifikan terhadap kepuasan pelanggan
H3 : Kualitas layanan berpengaruh signifikan terhadap kepuasan pelanggan

H4 : Harga, produk, pemasaran relasional dan MCSQ berpengaruh signifikan terhadap kepuasan pelanggan melalui kualitas layanan

\section{METODE PENELITIAN}

\section{a. Populasi, Sampel, Besaran Sampel}

Populasi penelitian adalah wisatawan domestik yang menginap di hotel bintang empat Kabupaten Badung Provinsi Bali yang rata-rata sebulan berjumlah 250 orang. Sampel pada penelitian adalah wisatawan domestik pada hotel bintang empat di Kabupaten Badung Provinsi Bali pada saat penelitian dilakukan yaitu tanggal 1-31 Juli 2016, berjumlah 154.

Teknik pengambilan sampel menggunakan purposive sampling. Responden dipilih berdasarkan kriteria sampel adalah wisatawan domestik yang menginap di hotel bintang empat di Kabupaten Badung Provinsi Bali. Metode yang digunakan untuk mengetahui besaran sampel yang dapat mewakili suatu populasi dilakukan dengan menggunakan rumus Slovin $(\mathrm{Hu}-$ sein, 2011), sehingga dari populasi sejumlah 250 responden, diperoleh jumlah responden yang dijadikan sampel adalah 154 orang. Dengan demikian teknik pengambilan sampel secara purposive sampling.

\section{b. Definisi Operasional Variabel}

1) Harga (X1) adalah kesesuaian manfaat dengan nilai pengorbanan menggunakan jasa hotel. Variabel harga (X1) secara operasional diukur menggunakan indikator-indikator berikut: tarif sesuai harapan (terjangkau), tarif sesuai manfaat dan tarif berdaya saing. yang diukur dengan skala Likert.

2) Produk (X2) adalah segala sesuatu yang ditawarkan hotel untuk digunakan atau dikonsumsi Indikator terhadap produk adalah sebagai berikut produk inti dan produk tambahan yang diukur dengan skala Likert.

3) Pemasaran Relasional (X3) adalah mempertahankan pelanggan dengan membangun hubungan jangka panjang. Pemasaran relasional diukur dengan indikator sebagai berikut: attracting, developing, dan retaining, yang diukur dengan skala Likert.

4) MCSQ (X4) adalah perilaku dalam 
menciptakan layanan prima MCSQ ini diukur dengan indikator sebagai berikut: pemberdayaan dan penghargaan yang diukur dengan skala Likert.

5) Kualitas layanan (Y1) adalah pemenuhan layanan yang melebihi harapan. Variabel kualitas layanan (Y1) secara operasional diukur menggunakan indikator-indikator sebagai berikut: tangible, reliable, responsiveness, assurance dan empathy yang diukur dengan skala Likert.

6) Kepuasan pelanggan (Y2) adalah sikap yang timbul dari perasaan setelah menggunakan dan mengkonsumsi jasa hotel. Variabel kepuasan pelanggan (Y2) secara operasional diukur menggunakan indikator-indikator berikut: minat beli ulang dan mereferensi yang diukur dengan skala Likert.

\section{c. Teknik Analisis Data}

Analisis penelitian ini menggunakan: Analisis deskriptif untuk dapat mengetahui bagaimana distribusi jawaban responden terhadap kuesioner yang meliputi variabel-variabel beserta masing-masing indikator yang menjadi pilihan responden dengan rata-rata dan Analisis SEM (Structural Equation Modeling) untuk menguji hipotesis.

\section{HASIL DAN PEMBAHASAN \\ a. Analisis SEM}

Hasil pengujian asumsi SEM membuktikan data berdistribusi normal dan tidak outlier. Hasil pengujian pemodelan secara keseluruhan nampak pada Gambar 2.

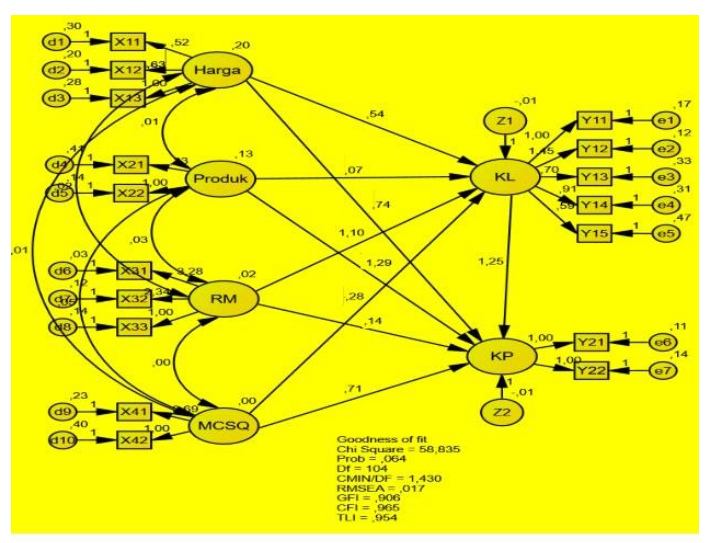

Gambar 2

Model Persamaan Struktural

Sumber:Data primeryang diolah, 2016

\begin{tabular}{ll} 
Keterangan : & \multicolumn{1}{c}{$\cdot$} \\
Harga & MCSQ \\
$\mathrm{X}_{1.1}=$ Tarif sesuai & $\mathrm{X}_{4.1}=$ Pemberdayaan \\
Harapan & $\mathrm{X}_{4.2}=$ Penghargaan \\
$\mathrm{X}_{1.2}=$ Tarif sesuai & \\
manfaat & $\mathrm{KL}$ (Kualitas Layanan) \\
$\mathrm{X}_{1.3}=$ Tarif & $\mathrm{Y}_{1.1}=$ tangible \\
berdaya saing & $\mathrm{Y}_{1.2}=$ reliable \\
& $\mathrm{Y}_{1.3}=$ responsiveness \\
Produk & $\mathrm{Y}_{1.4}=$ assurance \\
$\mathrm{X}_{2.1}=$ Produk Inti & $\mathrm{Y} 1.5=$ empathy \\
$\mathrm{X}_{2.2}=$ Produk & \\
tambahan & $\mathrm{KP}($ Kepuasan \\
& $\mathrm{Pelangan}$ \\
$\mathrm{RM}$ (Pemasaran & $\mathrm{Y}_{2.1}=$ minat beli \\
Relasional) & ulang \\
$\mathrm{X}_{3.1}=$ Attracting & $\mathrm{Y}_{2.2}=$ mereferensi \\
$\mathrm{X}_{3.2}=$ Developing & \\
$\mathrm{X}_{3.3}=$ Retaining &
\end{tabular}

b. Pembahasan

1) Pengaruh Harga, Produk, Pemasaran Relasional dan MCSQ Terhadap Kualitas Layanan

Harga yang digambarkan dari tarif berdaya saing, berupa tarif tambahan hotel yang wajar. Produk yang digambarkan dari produk tambahan yaitu kelengkapan fasilitas hotel yang melebihi harapan pelanggan, berupa sarana fitnes, spa, karaoke, convention hall yang luas. Pemasaran relasional yang digambarkan dari attracting berupa kemudahan prosedur members card hotel, sehingga mudah menggunakan produk tambahan yang ditawarkan, dan MCSQ yang digambarkan dari manajemen hotel berkomitmen memberdayakan staf menanggapi keluhan tamu hotel, menjadikan layanan hotel berkualitas, yang digambarkan dari reliable berupa hotel mengupayakan pencatatan (records) yang bebas dari kesalahan, seperti pencatatan identiitas tamu, billing, dan bukti pembayarannya.

Menginap di hotel bintang empat merupakan pilihan bagi pelanggan yang sedang berlibur mayoritas 2 - 3 hari, karena tarif layanan tambahan hotel wajar, hotel menawarkan produk tambahan yang dibutuhkan untuk melengkapi pengalaman berlibur, kemudahan memanfaatkan prosedur penggunaan member card hotel, dan manajemen hotel menanggapi keluhan tamu hotel, 
JURNAL CAKRAWARTI, Vol. 03 No. 02, Ags '20 - Jan '21

\begin{tabular}{|c|c|c|c|c|c|c|c|c|}
\hline \multirow{3}{*}{ Hip } & \multicolumn{3}{|c|}{ Variabel } & \multicolumn{4}{|c|}{ Koefisien } & \multirow{3}{*}{ Hasil } \\
\hline & \multirow[t]{2}{*}{ Eksogen } & \multirow[t]{2}{*}{ Mediasi } & \multirow[t]{2}{*}{ Endogen } & \multicolumn{2}{|c|}{$\begin{array}{l}\text { Pengaruh } \\
\text { Langsung }\end{array}$} & \multirow{2}{*}{$\begin{array}{c}\text { Pengaruh } \\
\text { Tidak } \\
\text { Langsung }\end{array}$} & \multirow{2}{*}{$\begin{array}{c}\text { Pengaruh } \\
\text { Total }\end{array}$} & \\
\hline & & & & Koef. & Prob. & & & \\
\hline \multirow{4}{*}{$\mathrm{H}_{1}$} & Harga $\left(\mathrm{X}_{1}\right)$ & - & $\begin{array}{l}\text { Kualitas } \\
\text { Layanan }\left(\mathrm{Y}_{1}\right)\end{array}$ & 0,804 & 0,000 & - & - & Teruji \\
\hline & Produk $\left(\mathrm{X}_{2}\right)$ & - & $\begin{array}{l}\text { Kualitas } \\
\text { Layanan }\left(\mathrm{Y}_{1}\right)\end{array}$ & 0,084 & 0,043 & - & - & Teruji \\
\hline & $\begin{array}{l}\text { Pemasaran } \\
\text { Relasional } \\
\left(\mathrm{X}_{3}\right)\end{array}$ & - & $\begin{array}{l}\text { Kualitas } \\
\text { Layanan }\left(\mathrm{Y}_{1}\right)\end{array}$ & 0,862 & 0,001 & - & - & Teruji \\
\hline & $\operatorname{MCSQ}\left(\mathrm{X}_{4}\right)$ & - & $\begin{array}{l}\text { Kualitas } \\
\text { Layanan }\left(\mathrm{Y}_{1}\right)\end{array}$ & 0,044 & 0,029 & - & - & Teruji \\
\hline \multirow{4}{*}{$\mathrm{H}_{2}$} & $\operatorname{Harga}\left(\mathrm{X}_{1}\right)$ & - & $\begin{array}{l}\text { Kepuasan } \\
\text { Pelanggan } \\
\left(\mathrm{Y}_{2}\right)\end{array}$ & 0,838 & 0,040 & - & - & Teruji \\
\hline & Produk $\left(\mathrm{X}_{2}\right)$ & - & $\begin{array}{l}\text { Kepuasan } \\
\text { Pelanggan } \\
\left(\mathrm{Y}_{2}\right) \\
\end{array}$ & 0,931 & 0,000 & - & - & Teruji \\
\hline & $\begin{array}{l}\text { Pemasaran } \\
\text { Relasional } \\
\left(\mathrm{X}_{3}\right) \\
\end{array}$ & - & $\begin{array}{l}\text { Kepuasan } \\
\text { Pelanggan } \\
\left(\mathrm{Y}_{2}\right)\end{array}$ & 0,501 & 0,032 & - & - & Teruji \\
\hline & $\operatorname{MCSQ}\left(\mathrm{X}_{4}\right)$ & - & $\begin{array}{l}\text { Kepuasan } \\
\text { Pelanggan } \\
\left(\mathrm{Y}_{2}\right)\end{array}$ & 0,085 & 0,030 & - & - & Teruji \\
\hline $\mathrm{H}_{3}$ & $\begin{array}{l}\text { Kualitas } \\
\text { Layanan } \\
\text { (Y1) }\end{array}$ & - & $\begin{array}{l}\text { Kepuasan } \\
\text { Pelanggan } \\
\left(\mathrm{Y}_{2}\right)\end{array}$ & 0,951 & 0,001 & - & - & Teruji \\
\hline \multirow{4}{*}{$\mathrm{H}_{4}$} & Harga $\left(\mathrm{X}_{1}\right)$ & $\begin{array}{l}\text { Kualitas } \\
\text { layanan }\end{array}$ & $\begin{array}{l}\text { Kepuasan } \\
\text { Pelanggan } \\
\left(\mathrm{Y}_{2}\right)\end{array}$ & 0,838 & & 0,765 & 1,603 & Teruji \\
\hline & Produk $\left(\mathrm{X}_{2}\right)$ & $\begin{array}{l}\text { Kualitas } \\
\text { layanan }\end{array}$ & $\begin{array}{l}\text { Kepuasan } \\
\text { Pelanggan } \\
\left(\mathrm{Y}_{2}\right)\end{array}$ & 0,931 & & 0,080 & 1,011 & Teruji \\
\hline & $\begin{array}{l}\text { Pemasaran } \\
\text { Relasional } \\
\left(\mathrm{X}_{3}\right) \\
\end{array}$ & $\begin{array}{l}\text { Kualitas } \\
\text { layanan }\end{array}$ & $\begin{array}{l}\text { Kepuasan } \\
\text { Pelanggan } \\
\left(\mathrm{Y}_{2}\right) \\
\end{array}$ & 0,501 & & 0,820 & 1,321 & Teruji \\
\hline & $\operatorname{MCSQ}\left(\mathrm{X}_{4}\right)$ & $\begin{array}{c}\text { Kualitas } \\
\text { layanan }\end{array}$ & $\begin{array}{l}\text { Kepuasan } \\
\text { Pelanggan } \\
\left(\mathrm{Y}_{2}\right)\end{array}$ & 0,085 & & 0,042 & 0,127 & Teruji \\
\hline
\end{tabular}

maka pelanggan menikmati layanan yang diberikan hotel.

Hasil penelitian sependapat dengan temuan penelitian yang dilakukan Parasuraman (2001), yang menyatakan bahwa harga secara signifikan mempengaruhi kualitas layanan. Zeithaml et al. (1996), yang menyatakan bahwa produk secara signifikan mempengaruhi kualitas layanan. Berry (2002), yang menyatakan bahwa pemasaran relasional secara signifikan mempengaruhi kualitas layanan. Tjahjono (2013), Kasiman (2014), yang menyatakan bahwa MCSQ secara signifikan mempengaruhi kualitas layanan.
2 Pengaruh Harga, Produk, Pemasaran Relasional dan MCSQ Terhadap Kepuasan Pelanggan

Harga yang digambarkan dari tarif berdaya saing berupa tarif tambahan hotel wajar. Produk digambarkan dari produk tambahan yang merupakan produk yang ditawarkan oleh hotel di luar dari produk inti yang ada. Pemberian produk-produk tambahan ini akan sangat bermanfaat bagi pelanggan, karena selain memanfaat produk inti yang ada pada suatu produk adanya produk tambahan ini akan menjadi variasi pilihan konsumen dalam menentukan pembelian, sehingga dengan adanya ragam produk tambahan ini akan semakin memberikan daya tarik pada pelanggan. 
Produk tambahan berupa kelengkapan fasilitas hotel yang melebihi harapan, pemasaran relasional digambarkan dari attracting berupa kemudahan prosedur pemegang members card hotel, dan manajemen hotel berkomitmen memberdayakan staf menanggapi keluhan tamu hotel, menjadikan pelanggan merasa puas yang dicerminkan dari minat beli ulang digambarkan pelanggan menginap lagi di hotel bintang empat jika ke Bali.

Harga dicerminkan dari tarif berdaya saing, yang paling diapresiasi adalah tarif layanan tambahan hotel wajar, berupa biaya resto, fitness, karaoke, spa, kafe, dan launch, sehingga tambahan tarif layanan hotel yang harus dibayar sebanding dengan kesempatan memperoleh layanan tambahan, menjadikan pelanggan memperoleh kepuasan dari layanan tambahan tersebut. Produk digambarkan dari produk tambahan yang dapat memuaskan keinginan atau kebutuhan pelanggan dari sekedar menginap, dicerminkan oleh kelengkapan fasilitas hotel yang melebihi harapan pelanggan. Ketersediaan kelengkapan fasilitas hotel yang disediakan, maka pelanggan akan merasa puas menginap di hotel bintang empat karena pelanggan dapat menikmati layanan dan fasilitas yang disediakan pihak hotel melebihi yang diharapkan. Pemasaran relasional dicerminkan dari attracting, yang paling diapresiasi adalah kemudahan prosedur pemegang members card hotel. Adanya kemudahan pemegang members card menjadikan pelanggan dapat menikmati fasilitas yang ditawarkan pihak hotel, sehingga pelanggan mendapatkan pengalaman dalam menikmati layanan dari fasilitas members card hotel yang melebihi harapan pelanggan menjadikan pengalaman selama menginap di hotel bintang empat memuaskan. MCSQ dicerminkan dari pemberdayaan, yang paling diapresiasi adalah manajemen hotel melatih staf terampil menanggapi keluhan tamu hotel, sehingga pelanggan merasa mendapat perhatian dari pihak manajemen hotel, hal ini menjadikan pelanggan merasa puas selama menginap di hotel bintang empat dan ingin menginap lagi di hotel yang sama.

Hasil penelitian sependapat dengan temuan penelitian yang dilakukan Parasuraman et al, (1999), Parasuraman (2001), yang menyatakan bahwa harga secara sig- nifikan mempengaruhi kepuasan pelanggan. Humphreys (1998), Prasastono dan Pradapa (2012), yang menyatakan bahwa produk secara signifikan mempengaruhi kepuasan pelanggan. Sefesiyani et al. (2015) dan Mutholib (2016), yang menyatakan bahwa pemasaran relasional secara signifikan mempengaruhi kepuasan pelanggan. Babakus et al. (2003); Nicholas and Jayne (2006), yang menyatakan bahwa MCSQ secara signifikan mempengaruhi kepuasan pelanggan

\section{Pengaruh Kualitas Layanan Terh- adap Kepuasan Pelanggan}

Kualitas layanan digambarkan dari reliable berupa memberikan layanan yang cermat, artinya tanpa kesalahan apapun, serta menyampaikan jasa sesuai dengan waktu yang disepakati yang dicerminkan dari hotel mengupayakan pencatatan (records) yang bebas dari kesalahan, akan menjadikan pelanggan merasa puas karena tidak mengalami kekeliruan dalam pencatatan, registrasi, pembayaran, dan pencatatan apapun serta layanan yang disajikan sesuai waktu yang dijanjikan, sehingga mendorong pelanggan untuk berminat menginap kembali ke hotel bintang empat di Bali.

Kualitas layanan merupakan keunggulan yang diharapkan dan pengendalian atas tingkat keunggulan tersebut untuk memenuhi keinginan pelanggan. Cara untuk mempertahankan pelanggan adalah memberikan jasa dengan kualitas layanan yang lebih tinggi dari pesaing secara konsisten dan memenuhi harapan pelanggan. Kualitas layanan yang baik akan meningkatkan kepuasan pelanggan. Sebaliknya kualitas layanan yang buruk akan menurunkan kepuasan pelanggan. Kualitas layanan dapat mempengaruhi kepuasan pelanggan. Hasil penelitian sependapat dengan temuan penelitian yang dilakukan Zeithaml et al. (1996), Prasastono dan Pradapa (2012), Zeithaml \& Parasuraman (1996), Duffy dan Ketchan (2008), yang menyatakan bahwa kualitas layanan secara signifikan mempengaruhi kepuasan pelanggan.

4. Pengaruh Harga, produk, pemasaran relasional dan MCSQ terhadap kepuasan pelanggan hotel bintang empat dengan kualitas layanan sebagai variabel intervening 
Kualitas layanan memediasi pengaruh harga, produk, pemasaran relasional dan MCSQ terhadap kepuasan pelanggan. Harga yang digambarkan dari tarif berdaya saing berupa tarif tambahan hotel wajar, produk digambarkan dari produk tambahan berupa kelengkapan fasilitas hotel yang melebihi harapan pelanggan, dan pemasaran relasional digambarkan dari attracting berupa kemudahan prosedur pemegang members card hotel, serta MCSQ yang digambarkan dari manajemen hotel berkomitmen memberdayakan staf menanggapi keluhan tamu hotel, disertai kualitas layanan digambarkan dari reliable dicerminkan dari hotel mengupayakan pencatatan (records) yang bebas darikesalahan, akan menjadikan pelanggan merasa puas karena tidak mengalami kekeliruan dalam pencatatan, registrasi, pembayaran, dan pencatatan apapun serta layanan yang disajikan sesuai waktu yang dijanjikan, sehingga mendorong pelanggan untuk berminat menginap kembali ke hotel bintang empat di Bali.

Harga berpengaruh dominan terhadap kepuasan pelanggan dengan mediasi kualitas layanan. Hal ini menunjukkan bahwa harga yang dicerminkan dari tarif berdaya saing, berupa tarif layanan tambahan hotel wajar, didukung dengan layanan yang berkualitas direfleksi oleh reliable, dicerminkan dari pencatatan (records) yang bebas dari kesalahan, karena tidak mengalami kekeliruan dalam pencatatan, misalnya pencatatan registrasi dan pembayaran, maka pelanggan tidak menderita kerugian karena kesalahan pembayaran ataupun data pelanggan, sehingga pelanggan merasa puas dan mendorong minat beli ulang untuk menginap lagi di hotel yang sama jika pelanggan membutuhkan jasa penginapan.

Jadi, harga yang berdaya saing, produk tambahan hotel yang terpenuhi, terbangunnya pemasaran relasional dan MSCQ yang memberdayakan staf untuk menangani keluhan pelanggan, disertai kualitas layanan yang tanpa kesalahan menjadikan pelanggan merasakan kepuasan menginap di bintang empat dan berkehendak untuk menginap kembali.
5. KESIMPULAN DAN SARAN
a. Kesimpulan
1) Harga, produk, pemasaran relasion-

al dan MCSQ berpengaruh terhadap kualitas layanan hotel bintang empat di Kabupaten Badung Provinsi Bali. Harga yang dicerminkan dengan tarif hotel yang sesuai harapan pelanggan, produk inti jasa hotel yang terpenuhi melalui keanggotaan yang menarik menjadi pelanggan hotel dan komitmen manajemen dalam memberdayakan staf hotel menjadikan layanan jasa hotel berkualitas dalam persepsi pelanggan yang dicerminkan dari jaminan pemesanan secara online.

2) Harga, produk, pemasaran relasional dan MCSQ berpengaruh terhadap kepuasan pelanggan hotel bintang empat di Kabupaten Badung Provinsi Bali. Tarif yang sesuai harapan pelanggan, produk inti jasa hotel yang terpenuhi, keanggotaan yang menarik menjadi pelanggan hotel dan komitmen manajemen dalam memberdayakan staf hotel akan memberikan kepuasan pelanggan hotel, sehingga mereferensi orang lain untuk menginap di hotel yang sama jika ke Kabupaten Badung Provinsi Bali.

3) Kualitas layanan berpengaruh terhadap kepuasan pelanggan hotel bintang empat di Kabupaten Badung Provinsi Bali. Pemesanan kamar yang dapat dilakukan secara online membuat konsumen merasakan kepuasan yang mendorong untuk mereferensi pada orang lain.

4) Harga, produk, pemasaran relasional dan MCSQ terhadap kepuasan pelanggan melalui kualitas layanan hotel bintang empat di Kabupaten Badung Provinsi Bali. Pemesanan kamar hotel secara online akan menentukan harga, produk, pemasaran relasional dan MCSQ terhadap kepuasan pelanggan yang dicerminkan merekomendasikan agar menginap di hotel yang sama pada pihak lain.

\section{b. Saran}

1) Bagi Pengembangan Ilmu

Memperkaya konsep kualitas layanan dan kepuasan pelanggan agar dapat diaplikasikan dalam pemasaran hospitality.

2) Bagi Pimpinan Manajemen Hotel

a) Mengembangkan strategi pemasaran khususnya pada har- 
ga agar selalu menarik, dengan memberikan besaran tarif yang sesuai manfaat dari penambahan-penambahan layanan yang diberikan.

b) Manajemen hotel berkomitmen memberdaykan staf melalui pelatihan agar dapat menangani keluhan tamu hotel.

3) Bagi Penelitian Lebih Lanjut

Peneliti lebih lanjut melanjutkan/ mengembangkan penelitian sekarang dengan menambahkan pengaruh gaya hidup terhadap kepuasan pelanggan.

\section{DAFTAR PUSTAKA}

Arnould, P., and Zinkhan, 2002. Consumer satisfaction. Consumers. New York: The McGraw-Hill Companies, 614653.

Ashill. 2008. The Effect Of Management Commitment To Service Quality On Frontline Employees' Affective And Performance Outcomes: An Empirical Investigation Of The Newzealand Public Healthcare Sector. Journal of Strategic Marketing. Vol. 16, No. 5, Hlm 437-462

Assauri, S., 2003. Customer Service yang Baik Landasan Pencapaian Customer Sarisfaction. Usahawan. No.01 Th. XXXII (Januari), pp.25-30.

Babakus, E., Bienstock, C.C., dan Van Scotter, J.R. 2004. Linking Perceived Quality and Customer Satisfaction to Store Traffic and Revenue Growth. Decision Sciences (35:4), pp 713-737.

Babakus, E., Yavas, U., Karatepe, O.M., \& Avci, T, 2003. The Effect Of Management Commitment To Service Quality On Employees' Affective And Performance Outcomes. Journal of the Academy of Marketing Science, 31(3): 272-286.

Band, W.A. 1991. Creating Value For Customers, Designing And Implementing A Total Corporate Strategy. Jihn wiley and sons inc. New York.

Berkowitz. 2002 Marketing, Third Edition, Irwin, Boston.

Berry LL, Zeithaml VA, Parasuraman, 1990. A. Quality counts in services too. Bus Horiz ; 28:44 - 52 (May/ June).

Berry, L., 2002, Relationship Marketing of Services Growing Interest: Emerging Perspectives, Journal of the Academy Marketing Science, Vol. 23. No.4.

Bitner, Marry. Jo., 1992. Servicescape: The Impact Of Physical Surrounding On Customer and Employees. Journal Of Marketing, 56 (2), 57-71.

Bowen, JT. and Chen SL. 1995, "The Relationship Between Customer Loyality and Customer Satisfaction. International of Contemporary Hospitality Management. Vol. 13 No. 5.

Chan, Syafruddin. 2003. Relationship Marketing: Inovasi Pemasaran yang Membuat Pelanggan Bertekuk Lutut. Cetakan Kedua. Jakarta: Penerbit Gramedia Pustaka Utama.

Cronin JJ, Taylor SA, 1992. Measuring service quality: a re-examination and extension. J Mark; 56: 55 - 68. July.

Daryanto. 2011. Sari Kuliah Manajemen Pemasaran. Bandung: PT Sarana Tutorial Nurani Sejahtera.

Duffy, Jo Ann M. and Alice A. Ketchand, 2008, An Examining The Role of Service Quality in Overall Service Satisfaction. Journal of Managerial Issues, Vol 10. No.2.

Dutka, Alan, 1994, AMA Handbook for Customer Satisfaction: A Complete Guidance to Research, Planning and Implementation, NTC Bussiness Books, Lincolnwood, Illionis.

Engel, J.F., R. Blackwell, dan C. Minnard. 2005. Consumer Behaviour. Eighth edition. The Dryden Press. Fort Worth.

Ferdinand, Augusty, 2006, Metode Pene- 
litian Manajemen: Pedoman Penelitian Untuk Penulisan Skripsi, Tesis, dan Disertasi Ilmu Manajemen, Semarang: Penerbit Badan Penerbit-Universitas Diponegoro.

Gefen, D., 2002. Customer Loyalty in ECommerce, Journal of the Association for Information Systems, 3:27-51.

Ghozali, I., 2007. Model Persamaan Struktural: Konsep dan Aplikasi dengan Program AMOS Ver. 5.0. BP Universitas Diponegoro, Semarang.

Goodwins, L dan Leech, N. 2006. Understanding Correlations: Factors That Affect The Size of r. The Journal Experimental education. 74 (3): 251-266.

Gronroos, C, 2000, "Service quality : the six criteria of good perceived servise quality“, Review of Business, Vol.9, Winter, pp. 10-13.

Gummesson, E. 1994, "Making Relationship Marketing Operational", International Journal of Service Industry Management, 5 (5), pp. 5-20.

Hartline, M.D., dan Ferrell, O.C. 1996. The management of customer-contact service employees: An empirical investigation. Journal of Marketing, 60, 52-70.

Hawkin, Del. I dan Lonney. 1997. Consumer Behavior Building Marketing Strategy. New York: McGraw-Hill Companies, Inc.

Hennig-Thurau, T., and Hansen. 2000. Why Customers Build Relationships with Companies - in this book in Service Competition, Lexington: Lexington.

Hoch, S.J., dan Deighton, J., 2009, "Managing What Consumers Learn from Experience", Journal of Marketing, Vol. 53, No. 2: 1 - 20.

$\mathrm{Hu}, \mathrm{H}$; J. Kandampully; and T.D. Juwaheer (2009), "Relationship and Impacts of Service Quality, Perceived Value, Customer Satisfaction, and
Image; An Empirical Study," The Service Industries Journal, Vol. 29, No. 2: 111-125.

Irawan, H., 1999. 10 Prinsip Kepuasan Pelanggan. Elex Media Komputindo.

Kasiman, 2014. Analisis Pengaruh Customer Value dan MCSQ terhadap Kepuasan Pelanggan dan Brand Image Di Rumah Sakit Ganesha Medika Purwosari Pasuruan. Disertasi. Program Pascasarjana Universitas Merdeka Malang.

Keller, K.L, 2007, Memory Factor in Advertising: The Effect of Advertising Retrieval Cues on Brand Evaluations, Journal of Customer Research, 14 (December),316-333.

Kotler, P and Keller K. L. 2006. Marketing Management, Twelfth Edition, Perason Education International, Singapore.

Kotler, P. and G. Amstrong. 2010. Principles of Marketing. Global Edition. 13 Edition, Pearson Education. 2012. Principles of Marketing. Global Edition. 14 Edition, Pearson Education.

Lewis, Robert C. and Bernard H. Booms. 2013. The Marketing Aspect Of Service Quality," in Emerging Perspectives on Services Marketing.

Lovelock, C,H and Wright, J. 2007. Service Marketing : People, Technology, Strategy, Sixth Edition, USA : Pearson Pretience Hall, PearsonEducation International.

Lupiyoadi, Rambat. 2001. Manajemen Pemasaran Jasa. Jakarta: Salemba empat.

Maholtra, Naresh K., and Avinandan Mukherjee, 2004. Analysing the Commitment Service Quality Relationship: A Comparative Study of Retail Banking Call Centres and Branches, Journal of Marketing Management.

Morgan, R., M., and Shelby D. Hunt, 2004, The Comminment Trust Theory of 
Relationship Marketing, Journal of Marketing, July.

Mowen, J.C., 1995, Consumer Behavior, Fourth Edition, International Edition, Englewood Cliffs, New Jersey: Prentice Hall Inc.

Mutholib. 2016. Pengaruh Marketing Relationship Terhadap Loyalitas Nasabah Melalui Kepuasan Nasabah Pada AJB Bumiputera 1912 Kantor Wilayah Medan Cabang Medan Baru. Jurnal Ilmiah Manajemen dan Bisnis. Vol. 17, No. 01: 52-65.

Oliver, R. L. 1997. Satisfaction: A behavioral perspective on the consumer. New York: McGraw- Hill.

Parasuraman, A. 2001. The Behavioral Consequenses of Service Quality. Journal of Marketing. Vol. 60.s

Parasuraman,A., Zeithaml, V.A., and Leonard L. Berry, 1988, SERVQUAL: A Multiple- Item Scale for Measuring Consumer Perceptions of Service Quality. Journal of Retailing. Vol 64 No 1, Spring, p12-40. . 1990, Delivering Quality Service : Balancing Customer Perceptions and Expectations, The Free Press, New York.

, 1991. Reassessment of expectation as a comparison standard in measuring service quality: Implication for further research. Journal of Marketing, 58 (January) 111-124.

Parvatiyar, A dan Sheth, J. N. 1995. Relationship marketing in consumer markets: antecedents and consequences. Journal of the Academy of Marketing Science. 23 (4): 255-27 1.

Peak, Wibur. J. 1992. Lesly's Handbook of Public Relations and Communications, Japan, Toppan Co. Ltd.

Peterson, Robert A, 1995, Relationship Marketing and the Consumer, Journal of the Academy of Marketing Science, 23 (4), 278-81.

Peterson, Robert A. and William, R.W.
1992, "Measuring Customer Satisfaction: Fact and Artifact", Journal of the Academy of Marketing Science, Vol. 20 (1), pp. 61-71.

Prasasti, R.D., Chaniago, H., dan Sutarso, Y., .2003, Pengaruh Relationship Marketing terhadap Kepuasan Pelanggan dalam Industri Jasa Asuransi Jiwa, Jurnal Ventura. Vol.6, No.2, Agustus 127-145.

Prasastono, Ndaru dan Sri Yulianto Fajar Pradapa. 2012. Produk dan Kualitas Pelayanan Terhadap Kepuasan Konsumen Kentucky Fried Chicken Semarang Candi. Dinamika Kepariwisataan. Vol. XI No. 2: 13-23.

Schneider. 1998. Linking Service Climate And Customer Perception Of Service Quality : Test Of A Causal Model, Journal Of Applied Psychology, Vol. 83: 150-163.

Sefesiyani, Atika, Achmad Fauzi DH dan Zainul Arifin. 2015. Pengaruh Relationship Marketing (Pemasaran Relasional) Terhadap Kepuasan Nasabah Serta Dampaknya Pada Loyalitas Nasabah (Survei padaNasabah Tabungan Bank Central Asia Kantor Cabang Pembantu Dinoyo Kota Malang). Jurnal Administrasi Bisnis (JAB). Vol. 28 No. 2 November 2015: 1-8

Shinta, Agustina. 2013. Manajemen Pemasaran. Malang: Universitas Brawijaya.

Sivesan, S. 2012. Customer Relationship Marketing and Company Satisfaction A Study On Mobile Service Providing Company In Srilanka. Global Journal Inc. Vol. 12 (18) 2012.

Sugiyono. 2013. Metode Penelitian Bisnis. CV Alvabeta, Bandung.

Sumarwan, Ujang. 2003. Perilaku Konsumen. Jakarta: Penerbit Ghalia Indonesia.

Sureshchandar, G.S., Chandrashekaran Rajendran dan R.N. Anantaraman, 2002, Determinant of Custom- 